\title{
The pudendal nerve and its branches in relation to the Richter's procedure
}

Sonè van der Walt, ${ }^{1,2}$ Anna Catherina Oettlé, ${ }^{1}$ Frans Jacob van Wijk ${ }^{3}$

${ }^{1}$ Department of Anatomy, School of Medicine, Faculty of Health Sciences, University of Pretoria, Gauteng, South Africa, '2Department of Anatomy, School of Pathology and Preclinical sciences, Faculty of Health Sciences, Sefako Makgatho Health Sciences University, Gauteng, South Africa, ${ }^{3}$ Department of Urology, Urology Hospital, Pretoria, Gauteng. South Africa

RUNNING HEAD: Pudendal nerve in relation to Richter's procedure

KEYWORDS: Pudendal nerve, inferior rectal nerve, Richter's procedure, sacrospinous ligament, vaginal prolapse, safe area.

*Correspondence to: S. van der Walt, Department of Anatomy, School of Medicine, Faculty of Health Sciences, University of Pretoria, Private Bag x323, Arcadia, Pretoria, 0007, Republic of South Africa. Tel: +27 83312 8485. E-mail: duplessis.son@gmail.com 


\section{Abstract}

Background/Aims: Variations in the branching pattern of the pudendal nerve (PN) have been described in the literature. This study investigated these variations in order to comment on a safe area for the placement of a Richter's stitch. Methods: The Richter's procedure was performed on nine unembalmed female cadavers and followed by dissection. PN dissections were done on another twenty embalmed female cadavers. Variations in the branching pattern of the PN were noted and the distance between the Richter's stitch placed and the PN/or inferior rectal nerve (IRN) were measured. Results: The IRN entered the gluteal region as a separate structure in 6/29 cases. The separate IRN was found to pass between $4.1 \mathrm{~mm}$ to $14.45 \mathrm{~mm}$ medial to the ischial spine in $18 / 29$ cases. In one case, the Richter's stitch was found to pierce the IRN. The distance between the stitch and the PN and/or IRN ranged from $0 \mathrm{~mm}$ to $17.8 \mathrm{~mm}$. Conclusions: To minimise the risk of nerve damage or entrapment, the Richter's stitch should be placed more than $20 \mathrm{~mm}$ from the ischial spine. This recommended area should be revised for different population groups, as variations and the incidence of variations thereof might exist between groups. 


\section{Introduction}

Vaginal vault prolapse is a known complication occurring in $0.2 \%-43 \%$ of individuals that undergo a hysterectomy [1-3]. Some studies report even higher incidences up to 50\% [4]. Swift and co-workers found that prior hysterectomy doubled the risk of developing severe prolapse [5]. It is also said that the risk increases with the number of vaginal childbirths and advancing age $[5,6]$. Vaginal prolapse may be treated by the placement of a Richter's stitch through the anterior or posterior vaginal wall and into the sacrospinous ligament [7-10]. This procedure was first described in 1968 by Richter [11]. The suggested location for the stitch placement varies between one-and-a-half- to two finger breadths (15 to $20 \mathrm{~mm}$ ) medial to the ischial spine [12-15].

The pudendal nerve (PN) originates from the sacral plexus (S2-S4) and exits the pelvis through the greater sciatic foramen to descend posterior to the sacrospinous ligament [1619]. It then passes anterior to the lateral third of the sacrotuberous ligament and medial or posterior to the ischial spine before it enters the perineum through the lesser sciatic foramen via Alcock's canal [20]. As the PN enters the canal, it gives rise to the inferior rectal nerve (IRN), which runs through the medial wall of the canal $[1,21]$. The IRN may also arise from the pudendal trunk before it enters the pudendal canal [19]. Various studies have described an incidence of $12.5-40 \%$ of individual gluteal entry of the IRN, where it did not branch from the PN in the gluteal region $[16,17,22,23]$. Towards the distal end of Alcock's canal, the pudendal nerve bifurcates, giving rise to two terminal branches, the perineal nerve and the dorsal nerve of the penis or clitoris $[21,24]$. The perineal nerve is mostly found in the superficial perineal pouch and divides into cutaneous posterior scrotal or labial branches and muscular branches, which supplies all the perineal muscles $[1,17,19,21]$. The dorsal nerve of the penis/clitoris (DNP/C) runs anteriorly above the internal pudendal artery, along the posteromedial border of the inferior pubic ramus in the deep perineal pouch. The nerve courses through the suspensory ligament of the penis/clitoris before running on the dorsal surface of the penis/clitoris [24]. The DNP/C is the primary sensory nerve that serves the male or female organs, especially the sensitive glans at the distal end [21].

During the Richter's procedure, the pudendal nerve (PN), sciatic nerve and inferior gluteal vessels are at risk when performing the suspension of the anterior or posterior vaginal wall to the sacrospinous ligament $[1,6,9,25]$. In the gluteal region, the PN descends posterior to the 
sacrospinous ligament and may be entrapped by a placed Richter's stitch [20]. Entrapment of the PN may result in loss of motor and/or sensory function, as well as chronic pain syndromes [12, 26]. Buttock pain is a common post-operative symptom after sacrospinous colpopexy. Cruikshank et al [27] reported a $15 \%$ incidence and Maher et al [28] reported a $14 \%$ incidence experienced buttock pain on the side of the fixation of buttock pain which resolved by six to twelve weeks post operatively in all cases. This may result from the dissection in the pararectal space, but resolves spontaneously [11, 28]. Sze and Karram [29] suggested that the gluteal pain could be due to injury to then nerves in the coccygealsacrospinous ligament complex. By taking note of the course and branching pattern of the PN, complications and postoperative pain might be reduced.

The objective of this study was to note the variations in the branching pattern of the PN posterior to the sacrospinous ligament and to comment on a safe area for stitch placement in a South African population group.

\section{Materials and Methods}

The study was conducted at the University of Pretoria, Department of Anatomy and was approved by the Student Ethics Committee of the University of Pretoria (S56/2012, approved 25 June 2012).

The Richter's procedure was performed, and the stitch placed (using the Capio device) through the right sacrospinous ligament, as described by Goldberg [9], by a registered urologist and gynecologist on a sample of nine female cadavers, comprising two of African ancestry and seven of European ancestry.

The bodies were all placed in the lithotomy position and an anterior approach was followed in the performance of the Richter's procedure in this study. A vertical incision was made in the anterior vaginal wall extending from the level of the bladder neck to the apex of the vagina. A plane was established between the pubocervical fascia and the vaginal skin with sharp dissection. The dissection was continued until the descending pubic ramus could be 
palpated laterally, from which blunt dissection was performed until the ischial spine could be palpated. The position of the sacrospinous ligament could then be determined by tracing it from its insertion on the ischial spine to its origin on the sacrum. The Capio device was advanced $2 \mathrm{~cm}$ (two fingers' width) medial to the ischial spine where the suture was placed, penetrating the sacrospinous ligament [9].

Dissections to investigate the relationships of the Richter's stitch to the PN and branches were performed one month post-embalmment in the dissection halls of the University of Pretoria. Another twenty female adult cadavers, comprising eleven of African ancestry and nine of European ancestry were dissected to investigate the branching pattern of the PN posterior to the sacrospinous ligament. After the skin, subcutaneous fat and gluteus maximus muscle were reflected laterally, the sacrotuberous ligament was cleaned and detached from the sacrum. The pudendal neurovascular bundle was visualised and the position of the Richter's stitch determined. Variations in the PN branching pattern posterior to the sacrospinous ligament were noted, as well as the position of the branches in relation to the ischial spine. Points used as landmarks during various perineal procedures were identified and the distances, between these points of interest and the PN and/or branches were measured. The distance between the PN and/or IRN to the sutures placed were measured with a digital sliding calliper. Relations were noted and predictions were made regarding the safety of this procedure.

\section{Results}

\section{Anatomy of the PN posterior to the sacrospinous ligament}

In six of the twenty nine cases (one of European ancestry and five of African ancestry), a separate entry of the inferior rectal nerve (IRN) into the gluteal region, not branching from the PN was noted. In eighteen of the twenty nine cases (six of European ancestry and twelve of African ancestry) the IRN was found passing medial to the ischial spine, as it either branched from the PN superior to the ligament, or entered the gluteal region as a separate structure. The distance varied from $4.1 \mathrm{~mm}$ to $14.45 \mathrm{~mm}$ medial to the ischial spine (Table 1). In the cases where the IRN entered the gluteal region 
as a separate structure or was found medial to the ischial spine, it encroached into the area available for stitch placement, placing it in danger for entrapment. In the remaining six of the twenty nine cases the IRN branched from the PN inferior to the sacrospinous ligament as described by the literature. In general a smaller distance between the placed stitch and the IRN was noted than with the PN (Table 2). The distance between the placed stitch and the PN and IRN varied from 4.1 to 23.5 $\mathrm{mm}$ and 0 to $17.8 \mathrm{~mm}$ respectively. In one female of African ancestry, the Richter's stitch was placed through the IRN, entrapping it (Fig. 1).

Table 1

Table 2

Figure $1 \mathrm{a}$ and $\mathrm{b}$

\section{Discussion}

The extent and spectrum of variations in the branching pattern of the pudendal nerve, posterior to the sacrospinous ligament were explored in this descriptive cadaver study. Awareness of these variations may improve intra-operative outcomes and post-operative pain. Measurements between the stitch placed and the various branches were used to predict a safe area for stitch placement. Taking cognisance of this safe area could prove to be important in the prevention of nerve entrapment during stitch placement.

In six of the twenty nine cases (one of European ancestry and five of African ancestry), the inferior rectal nerve (IRN) entered the gluteal region separately and did not branch from the PN as expected. In eighteen of the twenty nine cases (six of European ancestry and twelve of African ancestry) the IRN passed medial to the ischial spine at a distance of $4.1 \mathrm{~mm}$ to $14.45 \mathrm{~mm}$ medial to the ischial spine. Separate entry of the IRN into the gluteal region is not an uncommon occurrence and varies between populations and studies performed. Mahakkanukrauh et al. [16] reported a $20.5 \%$ occurrence in an Asian cadaver study, Shafik et al. [17] noted a $20 \%$ occurrence in an Egyptian 
cadaver study, Lazerou et al. [23] reported a $40 \%$ occurrence in an American cadaver study and Achtari et al. [30] a 10\% occurrence in an Australian cadaver study.

The distance between the placed stitch and the IRN ranged from piercing the nerve to $17.8 \mathrm{~mm}$ medial to, or away from the nerve. In one female of African ancestry, the stitch was placed at the inferior border of the sacrospinous ligament, entrapping the IRN. During the Richter's procedure, it is recommended that the stitch be placed between one-and-a-half to two fingers breadth (15 to 20 $\mathrm{mm}$ ) from the ischial spine $[9,13]$. This distance might be insufficient and especially a separate IRN if present could be endangered.

Therefore, in cases where the IRN entered into the gluteal region separately, a more medially placed PN and/or IRN may encroach into the area available for the placement of the stitch. The Richter's stitch should thus be placed at a minimum distance of $20 \mathrm{~mm}$, or two to two-and-a-half fingers breadth, from the ischial spine to avoid nerve damage. The stitch should also be placed through the middle portion and not at the inferior border, as it may entrap the PN and/or the IRN when branching from the PN before entering the pudendal canal.

Entrapment of the PN may result in loss of motor and/or sensory function, as well as chronic pain syndromes $[12,26]$ whereas entrapment of the IRN may lead to faecal incontinence [24].

Awareness and understanding of the anatomical variations of the pudendal nerve in relation to the ischial spine and sacrospinous ligament could minimise complications and postoperative pain following perineal surgery. It is recommended that the suggested area for stitch placement should be revised for different population groups, as the anatomy may vary between groups.

Despite the limited sample, the current study provides data on a greater number of individuals than previously reported. Variations in the branching pattern of the PN and the influence it has in the successful performance of the Richter's procedure were considered. These findings should be verified in a clinical setting. 


\section{Acknowledgements}

Dr. Z Abdool from Steve Biko Academic hospital for the initial procedures performed. Prof PJ Becker from the Medical Research Council for the statistical analysis of the data. Ms. B English from the research office of the University of Pretoria's faculty of health science is thanked for her language editing services.

\section{Disclosure of interest}

No conflicts of interest to declare.

\section{References}

1. Krissi H, Stanton SL: Bilateral iliococcygeus fixation technicque for enterocele and vaginal vault prolapse repair. Pelviperineology 2010;29:11-4.

2. Stekkinger E, van der Linden PJQ: A Comparison of Suprapubic and Transurethral Catherization on Postoperative Urinary Retention after Vainal Prolapse Repair: A Randomized Controlled Trial. Gynecol Obstet Invest 2011;72:109-116.

3. Özcan U, Güngör T, Ekin M, Eken S: Sacrospinous fixation fot the prolapsed vaginal vault. Gynecol Obstet Invest 1999;47:65-68.

4. Martins P, Silva-Filho AL, da Fonseca AMR, Santos A, Santos L, Mascarenhas T, Jorge RMN, Ferreira AJM: Biomechanical properties of vaginal tissue in women with pelvic organ prolapse. Gynecol Obstet Invest 2013;75:85-92.

5. Swift SE, Pound T, Dias JK: Case-control study of etiologic factors in the development of severe pelvic organ prolapse. Int Urogynecol J 2001;12:187-192.

6. Uzoma A, Farag K: Vaginal vault prolapse. Obstet Gynecol Int 2009; 1-9.

7. El Tohamy O: Sacrospinous Colpopexy. ASJOG 2006;3:32-7. 
8. Ko-Kivok-Yun P, Monrozies X, Ayoubi J, Elghaoui A, Reme J: Vaginal sacral-spinal fixation or Richter's procedure. Experience of a surgical team with 54 cases. Revue française de gynécologie et d'obstétrique 1995;90(12):525.

9. Goldberg RP: Sacrospinous Ligament Suspension Using the Capio ${ }^{\mathrm{TM}}$ Suture Capture Technique. J Eur Genito-urninary Dis 2007:74-81.

10. Richter K: Die chirurgiesche anatomie dervagaefixatio sacrospinalis vaginalis: en beitrag zur operativen behandlung des scheidenblindsasch prolapses. Geburtshilfe Fauenheilkd 1968;28:321-327.

11. Alevizon SJ, Finan MA: Sacrospinous colpopexy: management of postoperative pudendal nerve entrapment. Obstet Gynecol 1996;88(4, Part 2):713-5.

12. Roshanravan SM, Wieslander CK, Schaffer JI, Corton MM: Neurovascular anatomy of the sacrospinous ligament region in female cadavers: Implications in sacrospinous ligament fixation. Am J Obstet Gynecol 2007;197(6):660. e1 - e6.

13. Karram MM, Kleeman SD: Vaginal vault prolapse; in: Rock JA, Jones HW. ( $3^{\text {rd }}$ ed): TeLinde's operative gynecology. $9^{\text {th }}$ ed. Philadelphia: Lippincott Williams \& Wilkins; 2003. P. 999-1032.

14. Walters MD, Karram MM: Surgical treatment of vaginal vault prolapse and enterocele; in: Walters MD, Karram MM (eds): Urogynecology and reconstructive pelvic surgery. $3^{\text {rd }}$ ed. Philadelphia: Mosby; 2007. P.262-287.

15. Sagsoz N, Ersoy M, Kamaci M, Tekdemir I: Anatomical landmarks regarding sacrospinous colpopexy operations performed for vaginal vault prolapse. Euro J Obstet Gynecol Reprod Biol 2002;101(1):74-8. 
16. Mahakkanukrauh P, Surin P, Vaidhayakarn P: Anatomical study of the pudendal nerve adjacent to the sacrospinous ligament. Clin Anat 2005;18(3):200-5.

17. Shafik A, El-Sherif M, Youssef A, Olfat ES: Surgical anatomy of the pudendal nerve and its clinical implications. Clin Anat 1995;8(2):110-5.

18. Ramsden CE, McDaniel MC, Harmon RL, Renney KM, Faure A: Pudendal nerve entrapment as source of intractable perineal pain. Am J Phys Med Rehabil 2003;82(6):479-84.

19. Robert R, Prat-Pradal D, Labat J, Bensignor M, Raoul S, Rebai R, Leborgne J, Lardoux MC, Thiodet J: Anatomic basis of chronic perineal pain: role of the pudendal nerve. Surg Radiol Anat 1998;20(2):93-8.

20. Meeks GR, Grey JE: Nerve injury associated with pelvic surgery. [cited 2011, 13 August]; Available from: http://www.uptodate.com/store.

21. Moore KL, Dalley AF: Clinically Orientated Anatomy. 5 ed. Baltimore: Lippincott Williams and Wilkins; 2006.

22. Pirro N, Sielezneff I, Le Corroller T, Ouaissi M, Sastre B, Champsaur P: Surgical anatomy of the extrapelvic part of the pudendal nerve and its applications for clinical practice. Surg Radiol Anat 2009;31(10):769-73.

23. Lazarou G, Grigorescu BA, Olson TR, Downie SA, Powers K, Mikhail MS: Anatomic variations of the pelvic floor nerves adjacent to the sacrospinous ligament: a female cadaver study. Int Urogynecol J 2008;19(5):649-54.

24. Shafik A, Doss S: Surgical anatomy of the somatic terminal innervation to the anal and urethral sphincters: role in anal and urethral surgery. J Urol 1999;161(1):85-9. 
25. Verdeja AM, Elkins TE, Odoi A, Gasser R, Lamoutte C: Transvaginal sacrospinous colpopexy: anatomic landmarks to be aware of to minimize complications. Am J Obstet Gynecol 1995;173(5):1468-9.

26. Barksdale P, Gasser R, Gauthier C, Elkins T, Wall L: Intraligamentous nerves as a potential source of pain after sacrospinous ligament fixation of the vaginal apex. Int Urogynecol J $1997 ; 8(3): 121-5$

27. Cruikshank SH. Preventing post hysterectomy vaginal vault prolapse and enterocele during vaginal hysterctomy. Am J Obstet Gynecol 1987;156: 1433-1440.

28. Maher C., Murray C., Carey M., Dwyer PL., Agoni AM. Iliococcygeus or sacrospinous fixation for vaginal vault prolapse. Obstet Gynecol 2001; 98; 40-44.

29. Sze HM, Karram MM. Transvaginal repair of vault prolapse. Obstet Gynecol. 1997;89: 466475.

30. Achtari C, Mckenzie BJ, Hiscock R, Rosamilia A, Schierlitz L, Briggs CA, Dwyer PL: Anatomical study of the obturator foramen and dorsal nerve of the clitoris and their relationship to minimally invasive slings. Int Urogynecol J 2006;17(4):330-4. 
Table 1. Distance $(\mathrm{mm})$ between the ischial spine and the PN and/or IRN

\begin{tabular}{llll}
\hline Groups & & PN to ischial spine & IRN to ischial spine \\
& & & \\
\hline Females of European & $\mathrm{n}$ & $16 / 16$ & $11 / 16$ \\
ancestry & mean & 1.71 & 5.17 \\
& $\mathrm{SD}$ & 0 & 4.65 \\
& range & $0-5.95$ & $0-12.66$ \\
\hline Females of African & $\mathrm{n}$ & $13 / 13$ & $7 / 13$ \\
ancestry & Mean & 4.58 & 8.72 \\
& $\mathrm{SD}$ & 2.37 & 4.14 \\
& range & $0-8.40$ & $0-14.50$ \\
\hline All females & $\mathrm{n}$ & $29 / 29$ & $18 / 29$ \\
& Mean & 2.99 & 6.55 \\
& $\mathrm{SD}$ & 2.76 & 4.68 \\
& range & $0-8.40$ & $0-14.45$ \\
\hline
\end{tabular}

Table 2. Distance $(\mathrm{mm})$ between the Richter's stitch and the PN and/or IRN

\begin{tabular}{lccccccccccc}
\hline Measurement & $\mathrm{n}$ & EA & EA & EA & EA & EA & EA & EA & AA & AA & Mean \\
& & & & & & & & & & & \\
\hline PN to stitch & 9 & 19.41 & 6.85 & 9.61 & 13.0 & 23.5 & 4.1 & 18.1 & 18.7 & 6.9 & 13.02 \\
IRN to stitch & 5 & 11.93 & 2.28 & 3.05 & 6.5 & & & 17.8 & & 0 & 6.93 \\
& & & & & & & & & & & \\
\hline PN to ischial spine & 9 & 0 & 2.73 & 0 & 0 & 0 & 4.9 & 0 & 3.8 & 6.6 & 2.0 \\
\hline IRN to ischial spine & 5 & 1.11 & 7.3 & 12.66 & 2.9 & & & 0 & & 13.1 & 6.18 \\
\hline n:sample size, EA: European ancestry, AA: African ancestry & & & & & & & & & & & \\
\hline
\end{tabular}




\section{Figure legends}

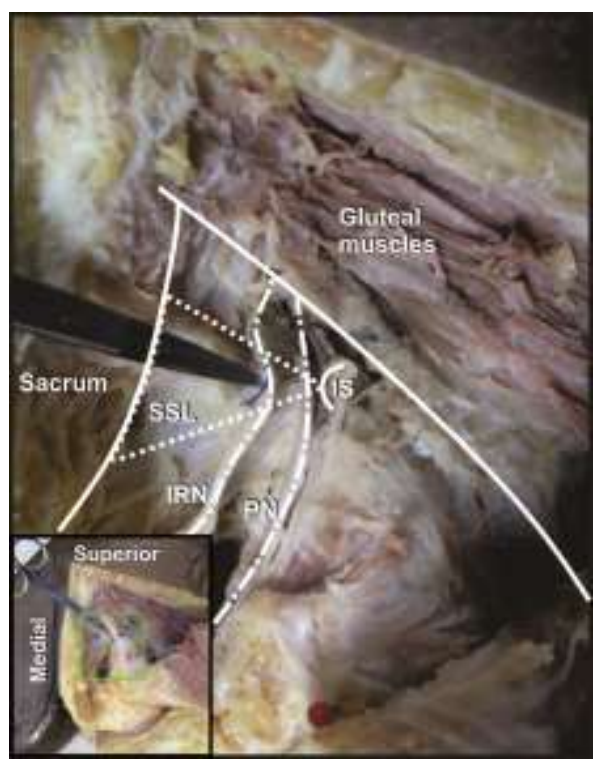

Figure 1a. The position of the Richter's stitch in relation to a separate entry of the IRN into the gluteal region.

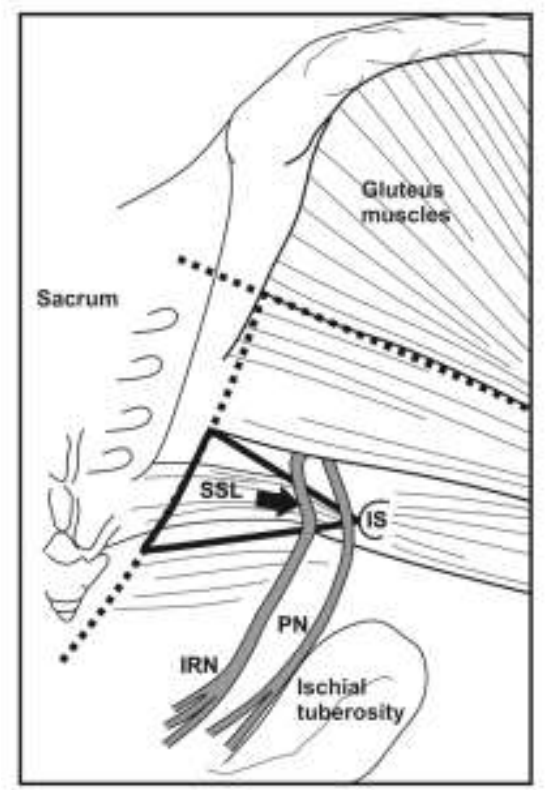

Figure 1b. Line diagram indicating the position of the Richter's stitch in relation to a separate entry of the IRN into the gluteal region.

SSL: sacrospinous ligament, IRN: inferior rectal nerve, PN: pudendal nerve, White arrow: Richter's stitch. 